\title{
COTIDIANIDADE DA MULHER QUE TEM HIV/AIDS: modo de ser diante da (im)possibilidade de amamentara
}

\author{
Stela M aris de M ello PAD OIN ${ }^{b}$, Ívis E mília de Oliveira SOU ZAc ${ }^{c}$, Cristiane Cardoso de PAU LA ${ }^{b}$
}

\section{RESUMO}

Investigação fenomenológica que objetivou compreender a cotidianidade da mulher infectada pelo vírus da imunodeficiência humana, diante da impossibilidade de amamentar. D esenvolveu-se entrevista com 12 mulheres, em um hospital universitário no sul do Brasil. Os depoimentos, analisados pelo método heideggeriano, revelaram que a mulher se mostra como serno-mundo e se mantém, predominantemente, na impessoalidade. Desvelou-se o modo de ser da de-cadência, expresso pela ocupação, falatório, curiosidade, ambigüidade e temor, além da inautenticidade do pacto de silêncio e do não dito. 0 cuidado solícito, mediado pela relação dialógica entre a mãe e o/ a filho/ a, entre a mulher e o/ a profissional, mostrou a possibilidade do movimento da inautenticidade para a autenticidade. Recomenda-se, como estratégia assistencial, o encontro vivido e dialogado, mediado pela escuta, empatia e intersubjetividade, que se desenvolva a partir da compreensão do modo de ser do humano diante das impossibilidades da condição sorológica e na busca de desvelar suas possibilidades.

D escritores: Saúde da mulher. Síndrome da imunodeficiência adquirida. A leitamento materno. F ilosofia em enfermagem.

\section{RESUMEN}

Investigación fenomenológica quetuvo como objetivo comprender la cotidianeidad dela mujer infectada por el vi rus dela inmunodeficiencia humana, ante la imposibilidad de amamantar. Se desar rolló una entrevista con 12 mujeres, en un hospital universitario en el sur de B rasil. L as declaraciones, analizadas por el método heideggeriano, revelaron quela mujer se muestra como ser-en-el-mundo y semantiene, predominantemente, en la impersonalidad. Se desveló el modo de ser de la decadencia, expresado por la ocupación, por las habladurías, curiosidad, ambigüedad y temor, además de la inautenticidad del pacto de silencio y de lo no dicho. E I cuidado solícito, mediado por la relación dialógica entre la madre y el/ la hijo/ a, entre la mujer y el/ la profesional, mostró la posibilidad del movimi ento de la inautenticidad para la autenticidad. Se recomi enda, como estrategia asi stencial, el encuentro vivido y dialogado, mediado por la escucha, empatía e intersubjetividad, que se desarrolla a partir de la comprensión del modo de ser del humano ante las imposibilidades de la condición serológica y en la búsqueda de desvelar sus posibilidades.

Descriptores: Salud de la mujer. Síndrome de inmunodeficiencia adquirida. L actancia materna. F ilosofía en enfermería. T itulo: Cotidianeidad de la mujer quetieneVIH / SIDA: modo de ser ante la (im)posibilidad de amamantar.

\section{ABST RACT}

The purpose of this phenomenological research is to understand the daily routine of women infected with the virus of human immunod eficiency (H IV) prevented from breastfeeding. T w elvew omen w ereinterview ed in a university hospital in souther $n$ B razil. T heir statements, analyz ed through a H eideggerian approach, show ed that the w omen reveal themselves as beings- in-the-world and are mainly impersonal. T heway of being of de cadencewas unveil led and expressed by occupation, gossip, curiosity, ambi guity, fear, and theinauthenticity of the pact of silenceand the unsaid. T he hel pful care mediated by a dialogic relationship betw een mother and son/ daughter, betw een the woman and the professional, show ed the possibility of movement from inauthenticity to authenticity. We recommend the use of direct and dialogued interaction as an assi stancestrategy, mediated by listening, empathy and intersubjectivity, and devel oped through the comprehension of the way of being of the human being in the face of the impossibilities imposed by the ser ological condition and in their attempt to unveil their possibilities.

D escriptors: N ursing. Women's health. A cquired Immunodeficiency Syndrome B reastfeeding. P hil osophy, nursing.

T itle: T he daily routine of women infected with H IV/ AID S: way of being in the face of the impossibility of breastfeeding.

\footnotetext{
${ }^{a}$ A rtigo originado da tese de D outorado apresentada em 2006 no Programa de Pós-G raduação em Enfer magem da E scola de E nfermagem Anna N ery (EEAN), U niversidade Federal do Rio de Janeiro (U FRJ), Rio de Janeiro, Brasil.

${ }^{\circ}$ D outora em E nfer magem, P rofessora A djunta do D epartamento de Enfer magem da U niversidade Federal de Santa M aria (U F SM ), Santa

M aria, Rio Grande do Sul, Brasil.

'D outora em Enfermagem, Professora T itular da EEAN/ U FRJ, Rio de Janeiro, Brasil.
} 


\section{INT RODUÇÃO}

0 aumento da participação das mulheres no perfil epidemiológico da Síndrome da I munodeficiência A dquirida (aids) evidencia a progressiva redução da razão de sexo entre todas as categorias de exposição. No Brasil, de 1980 até junho de 2008 foram notificados 333.485 casos de aids no sexo masculino e 172.995 no sexo feminino. O bserva-se que a razão de sexo ( $M$ :F ) vem diminuindo, passando de 15,1:1 em 1986 para 1,5:1 em 2006, mantendo-se em 2007(1).

Do ponto de vista biológico, a situação das mulheres infectadas pel o vírus da imunodeficiência humana (HIV) faz emergir a possibilidade de gestação. Com relação as gestantes, foram notificados 41.777 casos, desde $2000^{(1)}$. Diante da magnitude da problemática foi criado, no âmbito da Coordenação $\mathrm{N}$ acional de controle de D oenças Sexual mente T ransmissíveis (DST ), o G rupo A ssessor de M uIheres. Tem o objetivo assessorar na proposição e acompanhamento de políticas, princípios e diretrizes para as estratégias de promoção à saúde e prevenção de novos casos de infecção na população feminina(2).

Somadas aos investimentos nas políticas públicas em saúde, tem-se ações de prevenção da transmissão vertical do HIV e os desafios de uma prática de cuidado a gestantes e puér per as. A s normas para profissionais de saúde em mater nidades, da I niciativa H ospital A migo da Criança, propõem diretrizes assistenciais e referências para mulheres HIV positivas e outras que não podem amamentar ${ }^{(3)}$.

No cotidiano, as mulheres vivenciam a gestação com a possibilidade de transmissão do HIV para seu filho e isso se tor na uma de suas maiores preocupações(4). D evido ao preconceito, convivem com limitações no cuidado de si e na interação social(5). E ssas mul heres expressam esperança, fé, incertezas e buscam o significado da gestação e da vida ${ }^{(6-8)}$.

As mul heres ocultam sua condição sorológica de seus familiares e, por vezes, de seu companheiro sexual, por medo de conseqüências nas relações do cotidiano familiar, social e do trabal ho ${ }^{(9,10)}$. Convivem com a impossibilidade de amamentar, conduta identificada pelo enfaixamento dos seios, que é considerado doloroso e punitivo. No entanto, envolve a possibilidade de manter o bebê sadio, 0 que implica em aspectos biológicos, sociais, culturais e emocionais ${ }^{(11,12)}$.
Portanto, a partir da experiência de cuidado à mulher que tem $\mathrm{HIV} /$ aids e do entendimento da importância de compreender os sentimentos e significados que o ser humano confere às suas vivências, este estudo objetivou compreender a cotidianidade da mulher infectada pelo HIV, diante da impossibilidade de amamentar.

\section{TRAJET ÓRIA METODOLOGICA}

I nvestigação de natureza qualitativa, com abordagem fenomenológica e referencial teóricometodológico de $\mathrm{M}$ artin $\mathrm{H}$ eidegger ${ }^{(13)}$. A etapa de campo da pesquisa foi desenvolvida mediante a aprovação do Comitê de É tica em Pesquisa da U niversidade Federal de Santa M aria, Rio G rande do Sul (no 089/2004). 0 cenário da produção de dados foi o Hospital U niversitário de Santa M aria, que é referência para assistência de pessoas soropositivas ao HIV.

0 modo de acesso aos depoentes foi a entrevista fenomenológica(14,15). As mulheres tiver am sua inclusão voluntária mediante convite durante as atividades no grupo de apoio ambulatorial. 0 encontro foi mediado pela empatia e intersubjetividade $^{(16)}$, a partir da questão norteadora: como aconteceu a alimentação de seu filho? A partir da escuta atentiva, chegava à possibilidade de perguntar: qual foi o significado de não poder amamentar?

0 número de depoentes não foi determinado previamente, visto que a etapa de campo mostrou o quantitativo de entrevistas necessárias para responder ao objetivo da pesquisa. Então, com 12 entrevistas findou-se essa etapa, uma vez que os significados expressos nos depoimentos contemplaram as estruturas essenciais do fenômeno de investigação(17).

Os depoimentos foram gravados, mediante consentimento, e transcritos conforme fala original, apontando silêncios e expressões corporais. A análise contemplou os dois momentos metódicos heideggerianos: compreensão vaga emediana ehermenêutica(13).

0 primeiro momento metódico constou da suspensão de pressupostos do pesquisador ao desenvolver a escuta e leitura atentivas dos depoimentos, em busca de compreender a cotidianidade da mulher, sem impor-Ihe categorias predeter minadas pelo conhecimento teórico/ prática. Foram sublinhadas, nas transcrições, as estruturas essen- 
ciais, compondo um quadro de análise ${ }^{(13)}$. Assim, foram constituídas as unidades de significação com trechos dos depoimentos, de modo a ilustrar e compor o conceito vivido, que é o fio condutor da hermenêutica.

O segundo momento metódico desvelou os sentidos do ser, que se mostra a partir do primeiro movimento de análise. E sses sentidos foram interpretados segundo os conceitos teóricos do referencial filosófico de $\mathrm{M}$ artin H eidegger ${ }^{(13)}$. Possibilitou alcançar a essência do fenômeno cotidianidade da mulher que tem HIV/aids, desvelando facetas da dimensão existencial do seu modo de ser.

\section{RESULT ADOS E DISCUSSÃO}

As mulheres que tem $\mathrm{HIV}$ / aids sentem-se sozinhas, não falam com os outros sobre sua condição sorológica, por vezes, nem mesmo para o companheiro ou para os filhos/ as. Porém refletem que um dia terão que contar.

Só em casa eu não falo [ ...] o pai dela também não sabe [ ...] um dia decerto eu vou ter que contar não sei e cadê a coragem (M 2).

Porque é uma coisa que eu guardo só pra mim [ ...] nem pro meu marido (M 4).

$\mathrm{N}$ ão tive coragem deconta pra minha mãe, coitada [ ...] daqui há alguns dia dá pra conversa com ele [ referese ao filho] mais ou menos né? (M 6).

São trabal hadoras, cuidadosas e preocupadas com os/ as filhos/ as. Entre as atividades do dia-adia, apontam os cuidados com seus filhos/ as. Pensavam que tinha difer ença em cuidar, mas reconhecem que não tem. Percebem as crianças como normais, em busca de uma vida mel hor. Revelaram sua necessidade de trabal har para sentir que têm uma vida normal. 0 trabalho poderá ajudar a esquecer a doença, vão aprender coisas novas.

T ô dando suquinho devagarinho né, um mamazinho que eu fervo a água [ ...] trago elas aqui, faço minhas consulta, tem que comprar remédio, comprava. T rabaIho fora, vivo uma vida normal que todo mundo tem (M 1).

D epois que eu descobri que tô levando a vida nor mal, eu trabalho, me divirto, cuido das minhas filhas, normal (M 2).
M ostram-se aceitando os papéis que lhes são reservados pelos outros: cuidar dos filhos/ as e 0 serviço da casa. E m suas vivências conjugais, apontam o comportamento esperado do homem referindo-se a relacionamentos extraconjugais. Porém, reconhecem que não são vítimas e acreditavam que 0 casamento é seguro. D emonstram a conformidade com as situações, tanto em relação aos modos de ser mulher e de ser homem, quanto ao diagnóstico de infecção pelo HIV, pois relatam que fácil não é, mas tem que se conformar, é coisa da vida. A pontam a aceitação quanto ao que os profissionais da saúde dizem ou fazem, pois têm que acreditar neles, pois eles sabem mais que elas.

É coisa da vida, a gente tem que aceitar [ ...] o que tiver que ser né, vai levando (M 1).

M as da para ir levando [ ...] acho a maioria das muIher são assim também né, acreditam queo casamento é seguro e não é. Ainda mais no interior nunca ia pensar... masfoi, fazer o que.. agora tem quegüenta (M 2).

T u não usa camisinha, tu não usa nada. Aí ele saía chegava bêbado, mas ele não batia em mim nada, só chegava bêbado (M 3).

Expressam medo do preconceito, devido ao estigma da doença. A pontam as atitudes de discriminação que foram experiências de outras pessoas e vivências delas próprias. M ostram-se com medo de perder os amigos, os familiares e os/ as filhos/ as. $\mathrm{N}$ as instituições como creches e serviços assistenciais de saúde, as atitudes de discriminação também acontecem.

D aí tu sabe que é soropositivo, fica ali naquela expectativa, será que eles vão descobrir (M 2).

Ela sabe os probrema da minha guria, a vizinha do outro lado falou. E ntão ela não deixa nem a filha che ga perto (M 3).

T e cuida que ela... então me doeu. Varias vez es comentou com todas que trabalham lá. E u chegava e tava aquele clima [ ...] diferente (M 4).

T êm medo da doença que ameaça a vida e as faz pensar na morte e no que vai acontecer com seus filhos/as.

A minha irmã a mais velha mor reu do mesmo pobrema que eu tive, por causa da aids, mor reu uma amiga tam- 
bém. D aí eu perguntei pras guria se tomando remédio será que a gente vai morre junto? [...] um dia... se acontece comigo, aí eu fico chorando em cima da cama melembrando deles [ refere-se aos filhos] (M 3).

Sei queéhorrível os sintomas da doença [ ...] fica mau, tem infecções [ ...] ao menos fica com eles um pouquinho aqui $[$....] não sei o que vai se do futuro [ ...] se um dia eu fica mau mesmo eu vô te que conta [ refere-se aos filhos] (M 6).

$\mathrm{N}$ ão conhecem todos os sintomas, mas consideram horríveis, já ouviram falar ou acompanharam amigos, familiares ou sabem de pessoas com aids que já morreram. Porém, mesmo não sabendo quantos anos ainda Ihes restam, reforçam que, mesmo sendo ruim tomar os remédios, é com o tratamento que poderão viver mais e ficar com os/ as filhos/ as. T êm medo de morrer e deixar os/ as fiIhos/ as sozinhos/ as e não conseguem imaginar como vai ser.

As mulheres mostram-se com fé em Deus, rezam e pedem que a criança nasça sadia, sem HIV. R eferem que entregar am a sua vida na mão de $D$ eus e pedem mais uns anos de saúde, mesmo sabendo que dependem do remédio.

A pontam que recebem força nos/ as filhos/ as. Alguns sabem dos problemas e ajudam em casa, ficam com as outras crianças e, também, lembram a mãe da medicação. Quando elas se encontram sozinhas e com tristeza, mãe e filho/ a conver sam, as mães recebem carinho. Referem que encontram neles um amigo, que a entende e cuida. É pelos filhos/ as que se mantêm vivas e decidem tomar a medicação e não pelo cuidado de si.

M eu filho sabe de tudo, me ajuda [ ...] se eu tô chateada ele fica conversando comigo, eu boto a cabeça no colo dele e fica mexendo nos meus cabelo [ ...] as vezes eu choro no colo dele (M 5).

Que $D$ eus ajudasse que fosse diferente [ ...] se tive que toma vô toma pelo meu filho e não por mim (M 8).

Só entregar na mão de D eus, E le sabe o quefaze com a minha vida, se quisé cura (M 10).

Assim, neste estudo(18), a compreensão do modo de ser da cotidianidade da mulher que tem HIV/ aids diante da (im)possibilidade de amamentar desvelou vários sentidos a luz do referencial heideggeriano ${ }^{(13)}$, para esse artigo apresenta-se 0 sentido da de-cadência. Essa revela a impessoali- dade predominante na cotidianidade. As pessoas não se assumem em sua singularidade, misturando-se as características e expressões da maioria, sendo aquilo que esperam que sejam, repetindo os afazeres e dizeres de todos.

Observa-se que, de início, e na maioria das vezes, a mulher sucumbe ao impessoal e por ele se deixa dominar. $\mathrm{Na}$ convivência cotidiana, ela se mostra com uma fala comum e numa ocupação(13). No discurso relata que "fácil não é, mas tem que agüentar", ela se mantém ocupada com a síndrome fazendo o tratamento, trazendo seu/ sua filho/ a para as consultas ambulatoriais mensais, enfrentado as dificuldades que envolvem seu ser-no-mundo.

$N$ esse sentido, a de-cadência étentadora, como também é a possibilidade de perder-se no impessoal. "A pretensão do impessoal, de nutrir e dirigir toda a 'vida' autêntica, tranqüiliza a pre-sença, assegurando que 'tudo esta em ordem' e que todas as portas estão abertas"(13). A mulher expressa que "dá pra ir levando, a gente tem que enfrentar, tem que se confor mar, não adianta, é coisa da vida".

Permanecendo na ilusão de que tudo se compreende de modo universal, se "conduz a uma alienação na qual lhe encobre o seu poder-ser mais próprio. 0 ser-no-mundo da de-cadência, tentador e tranqüilizante é também alienante"(13). Desse modo, o ser "nunca se comunica no modo de uma apropriação originária, contentando-se em repetir e passar adiante a fala". A ssim, "as coisas são assim como são porque assim se falam delas"(13).

Deste modo, a mulher se ocupa com o que é falado e com o que ela fala da amamentação, da aids, do preconceito, da (im)possibilidade de amamentar e da morte. M ostra-se em um falatório, expressando que o que foi dito já foi sempre compreendido. No entanto, esse modo se ser é por si mesmo um fechamento, devido à falta de base e fundamento do referencial. É dessa maneira que a mulher conhece e aprende muitas coisas, e provavelmente não consegue ultrapassar uma compreensão mediana.

A mulher revela que tem medo da doença, presa àquilo que é o não dito. No falatório acerca da doença, refere que não conhece todos os sintomas, mas os considera horríveis, sabe que pode ter infecções e que pode morrer. Já ouviu falar ou acompanhou amigos, familiares que sofreram devido ao preconceito. A ssim, está na repetição do que se ouviu dizer e se expande no que se escreve e naquilo que se lê. 
Por isso, a mulher procura saber mais, apontando o modo de ser da curiosidade, que é o movimento de "ocupar-se em ver, não para compreender o que vê, mas apenas para ver". Assim, ela se ocupa em saber mais, buscar o novo, questiona acerca do tratamento e do desenvolvimento da doença, sem a pretensão de aprender, "apenas para tomar conhecimento"(13).

$\mathrm{N}$ a cotidianidade, a mul her que tem HIV/ aids mostra-se também na ambigüidade. E sse modo de ser evidencia-se quando "tudo parece ter sido compreendido, captado e discutido autenticamente quando, no fundo, não foi. 0 u parece que não o foi quando, no fundo, já foi"(13). I sso é expresso quando a mulher refere que gostaria de amamentar, mas não amamenta apesar de não entender por que não deve. Ela diz não entende por que está infectada, mas fala de suas relações, que não utilizou formas de prevenção e que não se cuidou. A crescenta que não sabe quantos anos de vida lhe restam e que é ruim tomar os remédios, mas que com os medicamentos vai "poder viver mais uns anos" e "ficar mais tempo" com os/ as filhos/ as, então segue o tratamento.

Tais modos de ser dominam a convivência, uma vez que o outro se faz presente pelo que se ouviu falar impessoalmente dele, ou pelo que se fala e se sabe ao seu respeito. Assim, todo mundo presta atenção em como o outro se comporta, no que ele irá dizer. Essa convivência impessoal trata de prestar atenção uns nos outros, de escutar secretamente ${ }^{(13)}$. Prestando atenção ao que falam da doença e da amamentação, a mulher não conta sobre seu diagnóstico e tem medo de que não amamentar revele sua situação sorológica para os outros.

Para esconder que tem HIV, responde com omissões aos questionamentos sobre por que está usando a mamadeira, ou com silêncio diante de comentários "como o bebê está bem; deve estar mamando no peito". Na maioria das vezes, a muIher não sabe o que vai dizer, quando sabe é por que anterior mente pensou e preparou uma resposta. Justifica o fato de não amamentar associado ao uso de medicamentos ou patologias comuns como a anemia.

A ssim, o não dito no discurso tem seu sentido no temor ${ }^{(13,18,19)}$ como modo de ser na convivência silenciosa com familiares, amigos e, muitas vezes, com o companheiro. Além disso, o que seria singular (o diagnóstico de aids) se torna público através de patologias aceitáveis no senso comum, e dessa forma a mulher se mantêm na impessoalidade.

Portanto, os modos de ser da ocupação, falatório, curiosidade, ambigüidade e temor, desvelados por meio dos significados e dos sentidos compreendidos nos resultados da pesquisa, mostram a de-cadência como predominante na cotidianidade da mulher que tem HIV/ aids. 0 sentido da de-cadência não exprime qualquer avaliação negativa, pretende afirmar que, quase sempre e na maioria das vezes, a presença está perdida na publicidade do impessoal(13). "N ão ser ele mesmo é uma possibilidade dos entes que se empenham essencial mente nas ocupações de mundo"(13).

De-cair no mundo indica o empenho na convivência, considerando que é conduzida pelos modos de ser da impessoalidade. Nesse sentido, a mulher revelou seu empenho na convivência, mostrou no discurso do não dito a necessidade de manter o sigilo e a sua necessidade de trabalhar para sentir que tem uma vida normal ou melhor.

E la trabal ha em casa nas lidas domésticas, fora de casa como camar eira, garçonete, vendedora, trabal ha na lavoura, na garimpagem de ferro vel ho ou como estudante. 0 trabal ho Ihe ajuda a esquecer a doença. Ao se compreender assim é como se não fosse ela mesma, incapaz de ser autêntica em assumir sua condição sorológica. É tomada pelo arbítrio dos outros, pelo que os outros vão dizer.

Presa em sua de-cadência e em meio a tantos medos que cercam a doença, a mulher pensa na morte como todo mundo pensa e fala, não a consider ando como possibilidade própria. Porém, a morte é esse fim como possibilidade ${ }^{(13)}$. O u seja, como possibilidade será a todo instante recusável, em nosso pensar sempre seremos ou muito jovens ou muito velhos para morrer.

N este estudo a mulher, pensa que vai morrer, assim como todo mundo sabe que tem que morrer um dia. No discurso do impessoal, refere que gostaria que fosse quando os/ as filhos/ as fossem adolescentes ou adultos, porque assim já teria autonomia de se cuidar e viver. G ostaria de deixar alguma coisa para seus filhos, inclusive o estudo, que os ajudasse para não passarem pelas mesmas situações por que passou. Assim, a mor te que é de cada um se torna um acontecimento público, é transferida para al gum dia futuramente.

Quando fala de seus filhos/as, refere que é deles que recebe a força ou a motivação para con- 
tinuar vivendo. Expressa o mundo compartilhado no ser-com-os-outros cotidiano, em que se mantêm nos extremos da solicitude: aquela que domina e que está impregnada pela desconsideração e pela negligência, e aquela que liberta que está impregnada pela consideração, paciência ou tolerância. A ssim, o cuidar solícito é compreendido como daquilo que estamos cuidando-com, e justamente com nossa compreensão dele. Assim, o outro é, de imediato, desvelado na solicitude cuidadosa ${ }^{(20)}$.

Pelos filhos/ as que a mulher decide tomar a medicação, e não pelo cuidado de si. A o pensar no filho que está gestando, considera que não pode ser egoísta ao pensar somente em si, então pensa nos/ as filhos/ as para conseguir enfrentar o tratamento e ter sucesso na prevenção da transmissão do HIV. T ambém aponta preocupação com o futuro de seu/ sua filho/ a e de "como vai ser...", mostrando a temporalidade como aspecto importante da singularidade; é o sentido de tempo próprio que emergiu. E la fala do futuro dos filhos, do seu vir-aser e os vê como ser de possibilidades. Relata que leva um tempo para aceitar sua condição sorológica e a (im)possibilidade da amamentação, compreendidas como facticidade, ou seja, como fatos dos quais não pode escapar. N ão se sabe em que tempo (cronológico) isso se dá, mas cada mulher terá um tempo (existencial) que é a expressão do sentido da temporalidade.

A ssim, a mulher também tem um tempo que Ihe singular para revelar seu diagnóstico para os outros com quem convive - "um dia vou ter que contar". Ela sabe que esse dia vai chegar, mas não sabe quanto tempo vai levar para compreender e enfrentar a possibilidade de contar, considerando o preconceito e a discriminação.

A temporalidade abre a possibilidade da autenticidade, ou seja, o movimento da inautenticidade do pacto de silêncio e/ ou do não dito para a autenticidade da revelação de seu diagnóstico e de seus filhos/ as.

\section{CONSIDERAÇÕES FINAIS}

0 modo de ser da de-cadência mantém a presença presa à sua tradição, privando de sua própria liderança, questionamento e escol has. $N$ esse modo de ser impessoal a mulher que tem HIV não está tomando decisão al guma sobre sua vida, mantémse em uma atividade publicamente reconhecida e aprovada.
O s resultados dessa pesquisa al ertam para esse modo de ser das mulheres que tem HIV, no qual estão absorvidas em suas ocupações cotidianas e presas à impessoalidade. $\mathrm{Na}$ maioria das vezes se mantém na de-cadência e continuam a pensar e agir de maneira tradicional. D esse modo a mulher sente-se confortável, acomodada, parecendo que tem menos problemas.

Portanto, a mulher diante da (im)possibilidade de amamentar devido ao HIV, descreve o seu mundo da vida, a sua historicidade, seu modo de ser da de-cadência pela temerosidade e ocupação. No entanto, aponta a possibilidade de autenticidade sol $\mathrm{i}$ dariedade e cuidado na relação de ser-com o/ a fiIha/ o e pelo diálogo com os profissionais.

A mulher contribui neste estudo mostrando a necessidade de um cuidado que a possibilite ser si mesma e a recuper ação da escol ha, que devolve a singularidade de ser, que ajuda a tornar-se mais, que liberta, que promove escol has e que possibilita decisões por si mesma.

Para o cotidiano assistencial, apontam a possibilidade de um cuidado que val orize as relações humanas e a interação profissional e mulher. Recomenda-se na implementação de políticas públicas, seja no controle da aids, seja no al eitamento materno, o desenvolvimento de um cuidado solícito, pautado na relação do ser-com que esteja aberto a compreensão autêntica da mulher em seu cotidiano, diante de suas impossibilidade e possibilidades. Como estratégia assistencial, 0 encontro vivido e dialogado, mediado pela escuta, empatia e intersubjetividade, se desenvolve a partir da compreensão do modo de ser do humano.

\section{REFERÊ NCIAS}

1 M inistério da Saúde (BR ), Secretaria de V igilância em Saúde, Programa Nacional de DST e Aids, U nidade de Informação e Vigilância. G ráfico 2: razão de sexo (M :F) dos casos de aids, segundo ano de diagnóstico: Brasil, 1983a2007. Bol E pidemiol AID ST . 2008;5(1):14.

2 M inistério da Saúde (BR), Secretaria de Programas deSaúde, Coordenação N acional de DST / AID S, U nidade de P revenção. Políticas e diretrizes de prevenção das DST / AID S entre mulheres. Brasília (DF ); 2002.

3 M inistério da Saúde (BR ), Secretaria de V igilância em Saúde, Secretaria de Atenção à Saúde. M anual normativo para profissionais da saúde de maternidadesreferência para mulheres que não podem amamentar. Brasília (DF); 2004. 
4 Preussler GM I, Eidt OR. Vivenciando as adversidades do binômio gestação e HIV/AIDS. Rev G aúcha Enferm. 2007;28(1):117-25.

5 Scherer L M , Borenstein M S, Padilha M I. G estantes/ puérperas com HIV/AIDS: conhecendo os déficits e os fatores que contribuem no engajamento para 0 autocuidado. Esc Anna N ery Rev Enferm. 2009;3(2): 359-65.

6 M artins JT, G aranhani M L, Robazzi M LC, Santos W C. Significados de qualidade de vida para mulheres convivendo com AID S. Rev G aúcha Enferm. 2008;29 (4):619-25.

7 M onticelli M, Santos EKA, Erdmann AL. Ser-mãe HIV-positivo: significados para mulheres HIV-positivo e para E nfer magem. A cta Paul E nferm. 2007;20(3): 291-8.

8 Coelho D F, M otta M G C. A compreensão do mundo vivido pelas gestantes portadoras do vírus da imunodeficiência humana (HIV). Rev G aúcha E nferm. 2005; 26(1):31-41.

9 Cechim PL, Selli L. M ulheres com HIV/ AID S: fragmentos de sua face oculta. Rev Bras Enferm. 2007; $60(2): 145-9$.

10 Vieira M , Padilha M I, Santos E. H istórias de vida: mãe e filho soropositivo para o HIV. T exto Contexto Enferm. 2009;18(1):33-40.

11 M oreno CCG S, Rea M F, F ilipe E V. M ães H IV positivo e a não-amamentação. Rev Bras Saúde M atern Infant. 2006;6(2):199-208.
12 Padoin SM M , Souza IE O. A ocupação da mulher com HIV/AIDS: o cotidiano diante da (im)possibilidade de amamentar. J Bras Sex T ransm. 2006;18(4):2416.

13 H eidegger M . Ser e tempo: parte I. 6ạ ed. Petrópolis: Vozes; 1997.

14 Carval ho AS. M etodologia da entrevista: uma abordagem fenomenológica. Rio de Janeiro: A gir; 1987.

15 Simões SM F, Souza IE O. U m caminhar na aproximação da entrevista fenomenológica. Rev L atino-A m Enfermagem. 1997;5(3):13-7.

16 Correa AK. Fenomenologia: uma alternativa para pesquisa em enfermagem. Rev L atino-A m E nfermagem. 1997;5(1):83-8.

17 Boemer M R. A condução de estudos segundo a metodologia de investigação fenomenológica. Rev Latino-Am Enfermagem. 1994;2(1):83-94.

18 Padoin SM M . O cotidiano da mulher com HIV/aids diante da (im)possibilidade de amamentar: um estudo na perspectiva heideggeriana [ tese] . Rio de Janeiro: E scola de E nfermagem A nna N ery, U niversidade Federal do Rio de Janeiro; 2006.

19 Padoin SM M , Souza IE O. A compreensão do temor como modo de disposição da mulher com HIV/ AIDS diante da (im)possibilidade de amamentar. Texto Contexto Enferm. 2008;17(3):510-8.

20 Heidegger $M$. Todos nós ninguém: um enfoque fenomenológico do social. São Paulo: M oraes; 1981.

Recebido em: 24/ 08/ 2009

A provado em: 21/ 12/ 2009

\section{Endereço da autora / Dirección del autor / Author's address: \\ Stela $M$ aris de $M$ ello Padoin \\ Av. Roraima, s/ n, prédio 26, sala 1336 \\ Cidade U niversitária, Bair ro Camobi \\ 97105-900, Santa M aria, R S \\ E-mail:padoinst@smail.ufsm.br}

